Received: 2015.01.15

Accepted: 2015.03.09

Published: 2015.07.01

\title{
Gonorrhea and Prostate Cancer Incidence: An Updated Meta-Analysis of 21 Epidemiologic Studies
}

Authors' Contribution: Study Design A Data Collection B Statistical Analysis C Data Interpretation D Manuscript Preparation E Literature Search F Funds Collection G

\author{
ABCDEF 1 Wen-Qing Lian* \\ ABCDEF 1 Fei Luo* \\ BD 2 Xian-Lu Song \\ DG 3 Yong-Jie Lu \\ ACDEG 1 Shan-Chao Zhao
}

1 Department of Urology, Nanfang Hospital, Southern Medical University, Guangzhou, Guangdong, P.R. China

2 Department of Radiotherapy, Cancer Center of Guangzhou Medical University, Guangzhou, Guangdong, P.R. China

3 Department of Molecular Oncology, Barts Cancer Institute, Barts and the London School of Medicine and Dentistry, Queen Mary University of London, London, U.K.
Corresponding Author: Source of support:

* These 2 authors contributed equally to this study and should be regarded as joint first authors Shan-Chao Zhao, e-mail: zhaoshanchaosmu@sina.cn

This study was supported by a grant from the National Natural Science Foundation of China (No. 81328017), two grants from Guangdong Provincial Science and Technology Projects of China (No. 2012B031800302, No. 2013B051000050), and two grants from President Foundation of Nanfang Hospital, Southern Medical University (No.G2011014, No.2013Z011)

Background: The association between gonorrhea and prostate cancer risk has been investigated widely, but the results remain inconsistent and contradictory. We conducted an updated meta-analysis to obtain a more precise estimate of this association.

Material/Methods:

PubMed, EMBASE, and the Cochrane Library were searched for papers up to June 2014 to identify eligible studies. Pooled odds ratios (ORs) and $95 \%$ confidence intervals (Cls) were calculated to assess the influence of gonorrhea on prostate cancer risk.

Results: Twenty-one observational studies (19 case-control and 2 cohort) were eligible, comprising 9965 prostate cancer patients and 118765 participants. Pooled results indicated that gonorrhea was significantly associated with increased incidence of prostate cancer (OR 1.31, 95\% Cl 1.14-1.52). The association between gonorrhea and prostate cancer was stronger in African American males (OR 1.32, 95\% Cl 1.06-1.65) than in Whites (OR 1.05, 95\% Cl 0.90-1.21).

Conclusions: Our findings suggest that gonorrhea is associated with an increased risk of prostate cancer, especially among African American males. These results warrant further well-designed, large-scale cohort studies to draw definitive conclusions.

MeSH Keywords: Gonorrhea • Meta-Analysis • Prostatic Neoplasms • Sexually Transmitted Diseases

Full-text PDF: http://www.medscimonit.com/abstract/index/idArt/893579

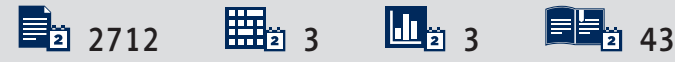




\section{Background}

Cancer of the prostate is the most frequently diagnosed cancer in men, accounting for $27 \%$ of new cancer cases in the United States (USA) in 2014. In the same year, $10 \%$ of the total cancer deaths in men were due to prostate cancer, the second leading cause of cancer death in this population [1]. Although the cause of prostate cancer remains unknown, its incidence has been associated with age, ethnicity, family history, physical activity, body mass index, diet, region, and sexually transmitted infections [2,3]. The seriousness of this disease warrants a more definitive investigation of its association with a history of sexually transmitted diseases.

Gonorrhea is a major public health concern worldwide. Caused by the bacterium Neisseria gonorrhoeae, in the year 2008 the World Health Organization estimated that there were 106 million infected adults globally, making it the most prevalent sexually transmitted bacterial infection [4]. Several epidemiologic studies have investigated an association between gonorrhea infection and incidence of prostate cancer, but results have been inconsistent. According to a meta-analysis published by Dennis et al. [5] in 2002, men with a history of gonorrhea were at elevated risk of prostate cancer (pooled relative risk ratio $[R R] 1.36,95 \%$ confidence interval $[\mathrm{Cl}] 1.15-1.61)$. A meta-analysis reported by Taylor et al. [6] in 2005 also indicated that gonorrhea was associated with increased prostate cancer risk (odds ratio [OR] 1.39, 95\% Cl 1.05-1.83). However, both of these studies were based predominantly on case-control data for white men. Studies that include African American subjects, serologic measures, and prospective data are lacking. More recently, 2 large, prospective, cohort studies $[7,8]$ and 2 case-control studies $[9,10]$ failed to confirm an association between a history of gonorrhea and prostate cancer. However, some factors were not considered in their analyses that might limit the evaluation of prostate cancer risk. These include adjustments for confounders, study design, study region, ethnicity, the method of gonorrhea exposure assessment, study quality, and the introduction of PSA screening.

Herein we provide an updated review and meta-analysis of the association between a history of gonorrhea and incidence of prostate cancer, conducting subgroup analyses based on the factors aforementioned.

\section{Material and Methods}

\section{Literature search}

We performed a systematic search of PubMed, EMBASE, and Cochrane Library databases, for all papers published up to June 2014. The following search terms were used: (gonorrhea
OR Neisseria gonorrhoeae OR sexually transmitted diseases OR sexually transmitted infections OR venereal disease) AND (prostate cancer OR prostatic neoplasms OR prostatic cancer OR prostate neoplasms). We also searched the reference lists of all the retrieved articles to identify any other potentially relevant articles.

\section{Study selection}

To be included in this meta-analysis, the papers had to report a case-control or cohort study; evaluate the association between gonorrhea and the incidence of prostate cancer; provide relative risk ratios, ORs, and $95 \% \mathrm{Cls}$, or sufficient information to calculate these; and be published in English. If multiple publications from the same study population were available, only the one with the largest sample size was included.

Studies were excluded if they did not conform to the inclusion criteria above, or contained duplicate data, or were based on incomplete raw data or irrelevant data. No case reports, letters, reviews, editorials, or correspondence articles were considered.

\section{Data extraction and quality score assessment}

Two investigators (Wen-Qing Lian and Fei Luo) independently reviewed and extracted information from all eligible publications, in accordance with the inclusion and exclusion criteria listed above. Disagreement was resolved by discussion between the 2 authors until a consensus was reached. If a consensus could not be reached, a third author (Xian-Lu Song) was consulted and a final decision was determined by majority opinion.

Data extracted from the publications included the first author, year of publication, country in which the study was performed, study design, study period, sample size, ages and ethnicities of the subjects, exposure assessment, and the confounders adjusted for. The subjects' ethnicities were categorized as white, African American, Asian, other, or mixed (a population with individuals of different ethnicities). For studies conducted in the USA, "blacks" were considered African Americans. When the paper did not specify the ethnicity of the study population, the most probable ethnicity was recorded, based on the predominant ethnic group in the study country.

The methodological quality of each eligible study was independently assessed by 2 reviewers (Wen-Qing Lian and Fei Luo) based on the Newcastle-Ottawa scale [11], in which the total score (in stars) can range from 0 to 9 . A third party (XianLu Song) was involved if a consensus could not be reached. A study was considered to be of high quality if the NewcastleOttawa Scale score was $\geq 7$ stars; studies given 5-6 stars were judged to be of moderate quality. 


\section{Statistical analysis}

Due to the low incidence of prostate cancer, the relative risk ratio can be mathematically approximated by the OR [12]. In the present study, the OR and its $95 \% \mathrm{Cl}$ was used to assess the association between gonorrhea and the risk of prostate cancer. In some studies, risk estimates were stratified according to ethnic categories, and risk to the total group was not reported. For these studies, the study-specific effect size in the overall analysis was recalculated using the inverse-variance method, by pooling the risk estimates of the various ethnic categories [13].

The statistical heterogeneity among the studies was evaluated using Cochrane's $Q$ test and the $R^{2}$ statistic. Regarding the former $(Q)$, heterogeneity was considered to exist for $P<0.1$. For $P>0.1$ and $I^{2}<50 \%$, the included studies were identified as having acceptable heterogeneity, and the fixed-effects model was used. Otherwise, the random-effects model was used [14,15].

To explore the sources of heterogeneity across studies, subgroup analyses were conducted according to study design (e.g., case-control vs. cohort study and population-based vs. hospital-based case-control study), geographic region (e.g., North America vs. Europe vs. Asia), adjustment of confounders (e.g., crude vs. adjusted), ethnicity (e.g., white vs. African American), exposure assessment (e.g., self-reported vs. medical record vs. serum antibody), and study quality (e.g., high vs. moderate). To determine whether estimates were influenced by the introduction of prostate-specific antigen (PSA) screening, we performed another subgroup analysis (i.e., pre-PSA vs. PSA-era screening) using 1994 as the cutoff [16].

For studies that spanned numerous years, we considered the middle year as the determining date. Sensitivity analyses were performed to assess the stability of the results. The influence of individual studies was evaluated by estimating the pooled ORs after omission of each study in turn. Potential publication bias was assessed by visual inspection of Begg's funnel plots, in which the log relative risk ratios were plotted against their standard errors. We also performed Begg's and Egger's tests to assess the presence of publication bias $[17,18]$. If the $P$-value for the Egger's test was $<0.05$, we assumed that there was publication bias. All of the statistical analyses were performed with STATA statistical software (version 12.0; College Station, TX), using 2-sided $P$-values.

\section{Results}

\section{Literature search}

Initially, we retrieved 605 articles from the PubMed, EMBASE, and Cochrane Library databases that were relevant to the search terms (Figure 1). Of these, 110 were removed as duplicates, which left 495 . By screening the titles and abstracts, 457 articles were excluded because they were reviews, editorials, or otherwise not relevant to our meta-analysis. Through fulltext review of the remaining 38 articles, 5 more were found by reviewing the reference lists, while 22 were excluded because the data were incomplete or irrelevant. Finally, 21 studies [7-10,19-35] were included for meta-analysis.

\section{Study characteristics}

Of the 22 included studies, 19 were case-control studies $[9,10,19-35]$ and 2 were cohort studies [7,8]; all were published between 1975 and 2011 (Table 1). Fourteen were conducted in North America [7-9,19-21,23,24,27,30-33,35], 5 in Europe [10,26,28,29,34], and 2 in Asia [22,25]. The sample size per study ranged from 104 to 68675 , with a total of 118765 participants and 9965 incident cases.

Most of these studies adjudged exposure or history of gonorrhea through self-report by the participants, while 2 used medical records [21,27] and 1 used serology for Neisseria gonorrhoeae antibodies [10]. The quality score of studies ranged from 5 stars to 9 stars according to the 9-star NewcastleOttawa Scale (Supplementary Table 1).

\section{Meta-analysis results}

Based on the combined results of the 21 studies, gonorrhea was significantly associated with increased risk of prostate cancer (OR 1.31, 95\% Cl 1.14-1.52) under the random-effects model (heterogeneity $I^{2}=38.2 \%, P=0.039$; Figure 2 ). The pooled OR did not substantially change even after adjustments for confounders, study quality, or the introduction of PSA screening (Table 2).

We also performed subgroup analyses based on study design, study region, ethnicity, and the method of gonorrhea exposure assessment (Table 2). In the subgroup analysis based on study design, we found a significantly increased risk of prostate cancer in the case-control studies (OR 1.41, 95\% Cl 1.24-1.61), especially in those that were population-based (OR $1.38,95 \% \mathrm{Cl}$ 1.19-1.61). However, the results from the cohort studies were nil (OR 1.07, 95\% Cl 0.95-1.21).

Regarding geographic area, there was a significant association between gonorrhea and prostate cancer risk in studies conducted in North America (OR 1.33, 95\% Cl 1.13-1.57), but no significant association was found in studies conducted in Europe (OR 1.18, 95\% Cl $0.78-1.78$ ) or Asia (OR 1.44, 95\% Cl 0.84-2.48). The association between gonorrhea and prostate cancer was higher for African American men (OR 1.32, 95\% $\mathrm{Cl} 1.06-1.65)$ than whites (OR 1.05, 95\% Cl 0.90-1.21). The 


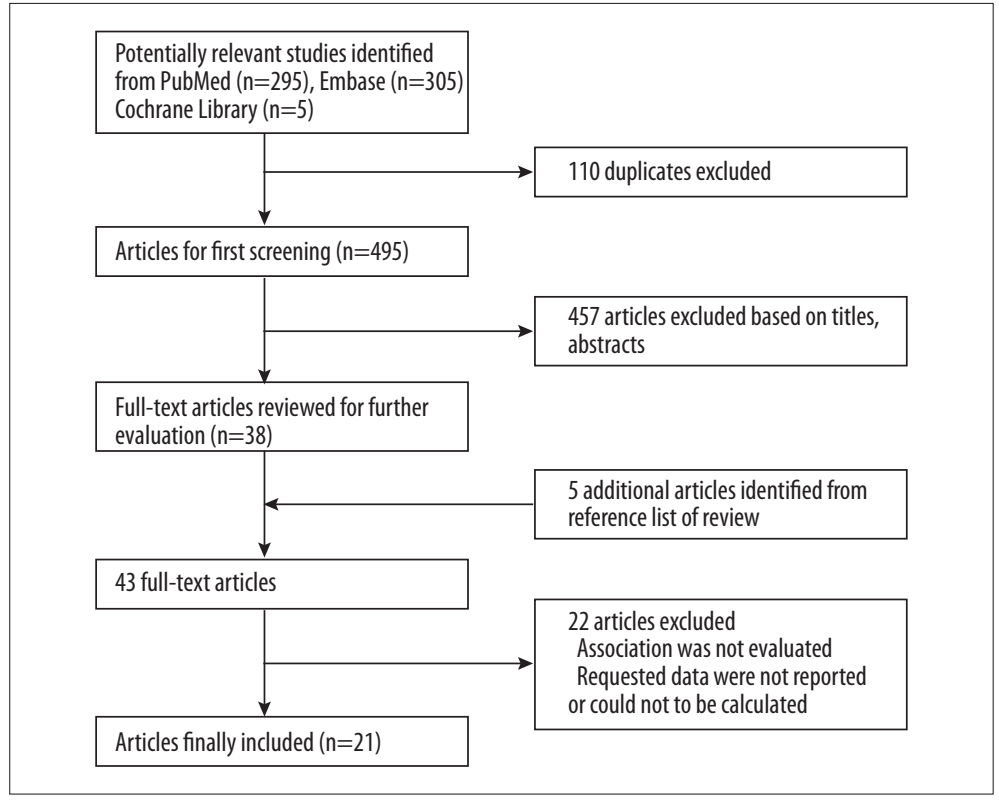

Figure 1. Flowchart showing study selection procedure.

association was more significant in studies relying on self-reports of gonorrhea exposure (OR $1.34,95 \% \mathrm{Cl} 1.15-1.57)$ than those that used medical records (OR $1.01,95 \% \mathrm{Cl} 0.56-1.82)$ or serum antibodies (OR $1.07,95 \% \mathrm{Cl} 0.42-2.73)$ to determine exposure.

\section{Sensitivity analysis}

To assess the influence of the individual data sets on the pooled ORs, repeated meta-analyses that excluded each single study in turn were performed. The corresponding pooled ORs were not materially altered.

\section{Publication bias}

Begg's funnel plot and Egger's test were conducted to assess the publication bias of the studies. The shape of the funnel plots did not reveal any evidence of obvious asymmetry (Figure 3 ), and the results indicated no publication bias $\left(P_{\text {Begg's }}=0.695, P_{\text {Egger's }}=0.054\right)$.

\section{Discussion}

We performed a meta-analysis of 21 relevant studies published up to June 2014 to determine the association between a history of gonorrhea and prostate cancer, and found a significantly increased risk of prostate cancer among men with prior gonorrhea.

Our results were consistent with the meta-analyses of case-control studies conducted by Dennis et al. [5] in 2002 and Taylor et al. [6] in 2005. However, the present meta-analysis involved 19 case-control studies and 2 cohort studies, and while a significant increased risk of prostate cancer was found from the casecontrol studies, the association according to the cohort studies was nil. The discrepancy between the case-control and cohort studies might be due to the potential bias of case-control studies, including selection bias or recall bias. We also found that there was a stronger association shown in population-based case-control studies than in hospital-based case-control studies. Although both population- and hospital-based case-control studies contain biases, we consider the former more reliable because the cases and controls are more representative.

In the present study, subgroup analyses by ethnicity revealed a stronger association between a history of gonorrhea and prostate cancer among African Americans than among whites. These results suggest that ethnic or cultural differences exist in susceptibility to prostate cancer after gonorrhea exposure. However, this finding should be cautiously interpreted. Data from the Centers for Disease Control and Prevention (CDC) in the United States showed that in 2012 the gonorrhea rate among African American males (467.7 cases per 100000 population) was 16 times the gonorrhea rate among white males (28.8 cases per 100000 population), and the disparities were striking across all age groups and regions [36]. Kwame OwusuEdusei Jr. et al. [37] also found that racial disparities in income were associated with racial disparities in gonorrhea rates. In addition, the higher gonorrhea rates might be due to the average lower rate of insurance, later diagnosis, less effective treatment, and greater incidence of relevant genetic polymorphisms in African Americans. Because rates of gonorrhea infection and rates of prostate cancer are each higher among African American men than among white men, we consider that many factors influencing these rates likely exist that are 
Table 1. Characteristics of the studies included in the meta-analysis.

\begin{tabular}{|c|c|c|c|c|c|c|c|c|c|}
\hline Authors,year & Country & Ethnicities & Design & Period & $\begin{array}{l}\text { Cases/ } \\
\text { subjects }\end{array}$ & Age, $y$ & $\begin{array}{l}\text { Evidence of } \\
\text { gonorrhea }\end{array}$ & $\begin{array}{l}\text { Crude / } \\
\text { adjusted }\end{array}$ & Quality \\
\hline $\begin{array}{l}\text { Baker et al., } \\
1981\end{array}$ & USA & Mixed & $\mathrm{HCC}$ & 1977-1979 & $44 / 134$ & $54-79$ & Self-report & Crude & 7 \\
\hline $\begin{array}{l}\text { Checkoway et al., } \\
1987\end{array}$ & USA & Mixed & $\mathrm{HCC}$ & 1984-1985 & $40 / 104$ & $50+$ & Self-report & Crude & 6 \\
\hline $\begin{array}{l}\text { Cheng et al., } \\
2010\end{array}$ & USA & AA, White, other & Cohort & $2002-2006$ & $1658 / 68675$ & $45-49$ & Self-report & Adjusted & 8 \\
\hline $\begin{array}{l}\text { Hayes et al., } \\
2000\end{array}$ & USA & $\mathrm{AA}^{*}$, White & PCC & 1993-1996 & $981 / 2296$ & $40-64$ & Self-report & Adjusted & 7 \\
\hline $\begin{array}{l}\text { Heshmat et al., } \\
1975\end{array}$ & USA & $A A^{*}$ & $\mathrm{HCC}$ & 1973-1978 & $75 / 150$ & NR & Self-report & Crude & 6 \\
\hline $\begin{array}{l}\text { Hiatt et al., } \\
1994\end{array}$ & USA & Mixed & PCC & 1978-1985 & $238 / 476$ & $>30$ & $\begin{array}{l}\text { Medical } \\
\text { record }\end{array}$ & Adjusted & 8 \\
\hline $\begin{array}{l}\text { Honda et al., } \\
1988\end{array}$ & USA & White & PCC & 1979-1982 & $216 / 432$ & $\leq 60$ & Self-report & Adjusted & 8 \\
\hline $\begin{array}{l}\text { Hrbacek et al., } \\
2011\end{array}$ & Czech Rep & White ${ }^{\star *}$ & $\mathrm{HCC}$ & 2004-2010 & $329 / 434$ & $64 / 72^{\star \star \star}$ & $\begin{array}{c}\text { Serum } \\
\text { antibody }\end{array}$ & Crude & 6 \\
\hline $\begin{array}{l}\text { Hsieh et al., } \\
1999\end{array}$ & Greece & White ${ }^{\star \star}$ & $\mathrm{HCC}$ & 1994-1997 & $320 / 566$ & All & Self-report & Crude & 5 \\
\hline $\begin{array}{l}\text { Huang et al., } \\
2008\end{array}$ & USA & $A A^{*}$, White, other & PCC & $1993-2001$ & $868 / 2151$ & $55-74$ & Self-report & Adjusted & 8 \\
\hline $\begin{array}{l}\text { Ilic et al., } \\
1996\end{array}$ & Serbia & White ${ }^{\star *}$ & $\mathrm{HCC}$ & 1990-1994 & $101 / 3037$ & $70.5 / 71.5^{\star * *}$ & Self-report & Crude & 6 \\
\hline $\begin{array}{l}\text { La Vecchia et al., } \\
1993\end{array}$ & Italy & White** & $\mathrm{HCC}$ & 1985-1990 & $271 / 956$ & $<80$ & Self-report & Adjusted & 7 \\
\hline $\begin{array}{l}\text { Lees et al., } \\
1985\end{array}$ & Canada & White ${ }^{\star \star}$ & $\mathrm{HCC}$ & 1962-1982 & $83 / 249$ & 69.9 & $\begin{array}{l}\text { Medical } \\
\text { record }\end{array}$ & Crude & 6 \\
\hline $\begin{array}{l}\text { Mishina et al., } \\
1985\end{array}$ & Japan & Asian** & PCC & 1976 & $100 / 200$ & $45-89$ & Self-report & Crude & 8 \\
\hline $\begin{array}{l}\text { Oishi et al., } \\
1989\end{array}$ & Japan & Asian** & $\mathrm{HCC}$ & 1981-1984 & $100 / 200$ & $70.6 / 70.0^{\star \star \star}$ & Self-report & Crude & 6 \\
\hline $\begin{array}{l}\text { Patel et al., } \\
2005\end{array}$ & USA & $A A^{*}$, White, other & PCC & 1996-1998 & $700 / 1304$ & $50-74$ & Self-report & Adjusted & 7 \\
\hline $\begin{array}{l}\text { Pelucchi et al., } \\
2006\end{array}$ & Italy & White ${ }^{\star \star}$ & $\mathrm{HCC}$ & 1985-1992 & $280 / 969$ & $<80$ & Self-report & Adjusted & 7 \\
\hline $\begin{array}{l}\text { Rosenblatt et al., } \\
2001\end{array}$ & USA & Mixed & PCC & 1986-1989 & $753 / 1456$ & $40-79$ & Self-report & Adjusted & 7 \\
\hline $\begin{array}{l}\text { Sanderson et al., } \\
2004\end{array}$ & USA & Mixed & PCC & 2000-2002 & $416 / 845$ & $65-79$ & Self-report & Adjusted & 7 \\
\hline $\begin{array}{l}\text { Sarma et al., } \\
2006\end{array}$ & USA & $A A^{*}$ & PCC & $1996-2001$ & $129 / 832$ & $40-79$ & Self-report & Adjusted & 7 \\
\hline $\begin{array}{l}\text { Sutcliffe et al., } \\
2006\end{array}$ & USA & Mixed & Cohort & $1992-2002$ & $2263 / 36033$ & $40-75$ & Self-report & Adjusted & 9 \\
\hline
\end{tabular}

AA - African American; HCC - hospital-based case-control; NR - not reported; PCC - population-based case-control; * For studies conducted in the USA, we categorized "Blacks" as African Americans; ${ }^{* *}$ No information on ethnicity in the paper. The ethnicity was taken to be the predominant ethnicity of the study country; ${ }^{* * *}$ The mean age of cases and controls. 
Supplementary Table 1. Quality assessment using the Newcastle-Ottawa Scale.

A. Methodologic quality of case-control studies included in the meta-analysis.

\begin{tabular}{|c|c|c|c|c|c|c|c|c|c|c|}
\hline & \multicolumn{4}{|c|}{ Selection } & \multicolumn{2}{|c|}{ Comparability } & \multicolumn{3}{|c|}{ Exposure } & \multirow[b]{2}{*}{$\begin{array}{r}\text { Total } \\
\text { quality } \\
\text { scores }\end{array}$} \\
\hline & $\begin{array}{l}\text { Adequate } \\
\text { definition } \\
\text { of cases }\end{array}$ & $\begin{array}{l}\text { Representa- } \\
\text { tiveness of } \\
\text { cases }\end{array}$ & $\begin{array}{c}\text { Selection } \\
\text { of control } \\
\text { subjects }\end{array}$ & $\begin{array}{l}\text { Definition } \\
\text { of control } \\
\text { subjects }\end{array}$ & $\begin{array}{l}\text { Study } \\
\text { controls for } \\
\text { age / } \\
\text { gender }\end{array}$ & $\begin{array}{l}\text { Study controls } \\
\text { for additional } \\
\text { factors }\end{array}$ & $\begin{array}{l}\text { Exposure } \\
\text { assessment }\end{array}$ & $\begin{array}{l}\text { Same method of } \\
\text { ascertainment } \\
\text { for cases and } \\
\text { controls }\end{array}$ & $\begin{array}{l}\text { Non- } \\
\text { Response } \\
\text { rate }\end{array}$ & \\
\hline Baker et al., 1981 & + & + & - & + & + & + & - & + & + & 7 \\
\hline Checkoway et al., 1987 & + & + & - & + & - & - & + & + & + & 6 \\
\hline Hayes et al., 2000 & + & + & + & + & + & + & - & + & - & 7 \\
\hline Heshmat et al., 1975 & + & + & + & - & + & - & - & + & + & 6 \\
\hline Hiatt et al., 1994 & + & + & + & + & + & + & - & + & + & 8 \\
\hline Honda et al., 1988 & + & + & + & + & + & + & - & + & + & 8 \\
\hline Hrbacek et al., 2011 & + & + & - & + & - & - & + & + & + & 6 \\
\hline Hsieh et al., 1999 & + & + & - & + & - & - & - & + & + & 5 \\
\hline Huang et al., 2008 & + & + & + & + & + & + & - & + & + & 8 \\
\hline Ilic et al., 1996 & + & + & - & + & + & + & - & + & - & 6 \\
\hline La Vecchia et al., 1993 & + & + & - & + & + & + & - & + & + & 7 \\
\hline Lees et al., 1985 & + & + & - & + & + & - & - & + & + & 6 \\
\hline Mishina et al., 1985 & + & + & + & + & + & + & + & + & - & 8 \\
\hline Oishi et al., 1989 & - & + & - & + & + & + & - & + & + & 6 \\
\hline Patel et al., 2005 & + & + & + & + & + & + & - & + & - & 7 \\
\hline Pelucchi et al., 2006 & + & + & - & + & + & + & - & + & + & 7 \\
\hline Rosenblatt et al., 2001 & + & + & + & + & + & + & - & + & - & 7 \\
\hline Sanderson et al., 2004 & + & + & + & + & + & + & - & + & - & 7 \\
\hline Sarma et al., 2006 & + & + & + & + & + & + & - & + & - & 7 \\
\hline
\end{tabular}

B. Methodologic quality of cohort studies included in the meta-analysis.

\section{Sutcliffe et al., 2006 Cheng et al., 2010}

\begin{tabular}{|c|c|c|c|}
\hline \multirow[t]{4}{*}{ Selection } & Representativeness of the exposed cohort & + & + \\
\hline & Selection of the unexposed cohort & + & + \\
\hline & Ascertainment of exposure & + & - \\
\hline & Outcome of interest was not present at start of study shown & + & + \\
\hline \multirow[t]{2}{*}{ Comparability } & Study controls for age/gender & + & + \\
\hline & Study controls for additional factors & + & + \\
\hline \multirow[t]{3}{*}{ Outcome } & Assessment of outcome & + & + \\
\hline & Follow-up long enough for outcomes & + & + \\
\hline & Adequacy of follow up & + & + \\
\hline Quality score & & 9 & 8 \\
\hline
\end{tabular}

\section{0}

- [Current Contents/Clinical Medicine] [SCI Expanded] [ISI Alerting System] [ISI Journals Master List] [Index Medicus/MEDLINE] [EMBASE/Excerpta Medica] [Chemical Abstracts/CAS] [Index Copernicus] 


\begin{tabular}{|c|c|c|c|}
\hline Study ID & & OR $(95 \% \mathrm{Cl})$ & $\%$ weight \\
\hline Heshmat (1975) & $\longrightarrow$ & $2.02(1.05,3.87)$ & 3.77 \\
\hline Baker (1981) & $1 \quad \longrightarrow$ & $4.98(2.21,11.21)$ & 2.64 \\
\hline Lees (1985) & 1 & $0.84(0.41,1.72)$ & 3.24 \\
\hline Mishina (1985) & & $1.32(0.69,2.55)$ & 3.75 \\
\hline Checkoway (1987) & $\rightarrow$ & $1.31(0.33,5.20)$ & 1.02 \\
\hline Honda (1988) & - & $1.40(0.80,2.60)$ & 4.39 \\
\hline Oishi (1989) & & $1.75(0.66,4.63)$ & 1.93 \\
\hline La Vecchia (1993) & & $0.70(0.20,2.40)$ & 1.24 \\
\hline Hiatt (1994) & - & $1.50(0.50,4.20)$ & 1.65 \\
\hline Ilic (1996) & & $8.69(1.00,350.66)$ & 0.24 \\
\hline Hsieh (1999) & & $1.41(0.81,2.45)$ & 4.81 \\
\hline Hayes (2000) & & $1.50(1.10,2.00)$ & 9.71 \\
\hline Rosenblat (2001) & & $1.50(1.02,2.18)$ & 7.72 \\
\hline Sanderson (2004) & & $1.27(0.77,2.08)$ & 5.58 \\
\hline Patel (2005) & & $1.00(0.50,1.50)$ & 4.86 \\
\hline Pelucchi (2006) & & $0.64(0.20,20.3)$ & 1.41 \\
\hline Sarma (2006) & $\rightarrow$ & $1.78(1.13,2.79)$ & 6.31 \\
\hline Sutclife (2006) & 1 & $1.04(0.79,1.36)$ & 10.48 \\
\hline Huang (2008) & $\rightarrow$ & $1.18(0.83,1.67)$ & 8.42 \\
\hline Cheng (2010) & $\rightarrow$ & $1.08(0.95,1.23)$ & 14.75 \\
\hline Hrbacek (2011) & & $1.07(0.42,2.73)$ & 2.07 \\
\hline Overall $(I-$ squared $=38.2 \%, p=0.039)$ & 1) & $1.31(1.14,1.52)$ & 100.00 \\
\hline ote: Weights are from random effects analysis & & & \\
\hline .5 & 2 & & \\
\hline
\end{tabular}

Figure 2. Forest plot and meta-analysis of the association between gonorrhea and prostate cancer risk.

Table 2. Overall and subgroup analyses of the association between gonorrhea and the risk of prostate cancer.

\begin{tabular}{|c|c|c|c|c|c|c|c|c|}
\hline \multirow{2}{*}{ Subgroup } & & \multirow{2}{*}{$\begin{array}{c}\text { Studies, } \\
\text { n }\end{array}$} & \multirow{2}{*}{$\begin{array}{c}\text { Cases, } \\
\text { n }\end{array}$} & \multirow{2}{*}{$\begin{array}{c}\text { Population, } \\
\mathbf{n}\end{array}$} & \multirow{2}{*}{ OR $(95 \% \mathrm{Cl})$} & \multicolumn{3}{|c|}{ Study heterogeneity } \\
\hline & & & & & & $\boldsymbol{Q}$ & $\boldsymbol{P}$ & $I^{2}, \%$ \\
\hline Overall & & 21 & 9965 & 118765 & $1.31(1.14-1.52)$ & 32.38 & 0.039 & 38.2 \\
\hline \multirow{2}{*}{ Confounding adjustment } & Crude & 9 & 1192 & 2340 & $1.65(1.12-2.43)$ & 15.17 & 0.056 & 47.3 \\
\hline & Adjusted & 12 & 8773 & 116425 & $1.17(1.07-1.28)$ & 12.49 & 0.328 & 11.9 \\
\hline \multirow{4}{*}{ Study design } & Case-control study & 19 & 6044 & 14057 & $1.41(1.24-1.61)$ & 22.99 & 0.191 & 21.7 \\
\hline & Hospital-based & 10 & 1643 & 4065 & $1.49(0.97-2.28)$ & 18.75 & 0.027 & 52.0 \\
\hline & Population-based & 9 & 4401 & 9992 & $1.38(1.19-1.61)$ & 3.94 & 0.862 & 0.0 \\
\hline & Cohort study & 2 & 3921 & 104708 & $1.07(0.95-1.21)$ & 0.06 & 0.806 & 0.0 \\
\hline \multirow{3}{*}{ Geographic region } & North America & 14 & 8464 & 115137 & $1.33(1.13-1.54)$ & 26.13 & 0.016 & 50.3 \\
\hline & Europe & 5 & 1301 & 3228 & $1.18(0.78-1.78)$ & 5.60 & 0.231 & 28.6 \\
\hline & Asia & 2 & 200 & 400 & $1.44(0.84-2.48)$ & 0.22 & 0.638 & 0.0 \\
\hline \multirow{2}{*}{ Ethnicity } & White & 10 & 3884 & 49481 & $1.05(0.90-1.21)$ & 10.40 & 0.319 & 13.5 \\
\hline & African American & 6 & 1403 & 8920 & $1.32(1.06-1.65)$ & 9.46 & 0.092 & 47.2 \\
\hline \multirow{3}{*}{ Exposure assessment } & Self-report & 18 & 9315 & 117606 & $1.34(1.15-1.57)$ & 31.15 & 0.019 & 45.4 \\
\hline & Medical record & 2 & 321 & 725 & $1.01(0.56-1.82)$ & 0.78 & 0.376 & 0.0 \\
\hline & Serum antibody & 1 & 329 & 434 & $1.07(0.42-2.73)$ & - & - & - \\
\hline \multirow{2}{*}{ Quality of study } & High & 14 & 8917 & 116759 & $1.19(1.09-1.31)$ & 24.65 & 0.026 & 47.3 \\
\hline & Moderate & 7 & 1048 & 2006 & $1.41(1.04-1.92)$ & 6.69 & 0.350 & 10.4 \\
\hline \multirow{2}{*}{ PSA screening } & Pre-PSA* & 12 & 2301 & 5629 & $1.51(1.11-2.05)$ & 18.40 & 0.073 & 40.2 \\
\hline & PSA era** & 9 & 7664 & 113136 & $1.16(1.05-1.27)$ & 9.01 & 0.342 & 11.2 \\
\hline
\end{tabular}

* Prior to July 1994; ** July 1994 or later. 


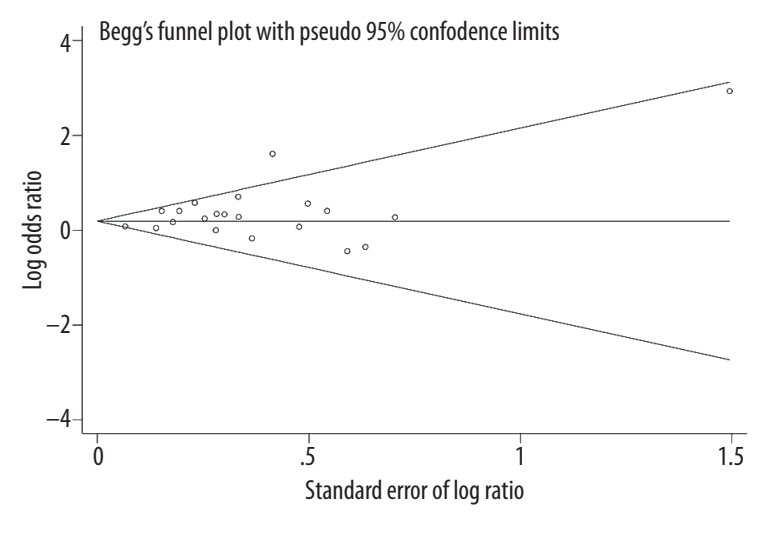

Figure 3. Begg's funnel plot of gonorrhea and prostate cancer risk.

beyond the scope of this analysis, and any conclusions require further verification.

In the present meta-analysis, subgroup analysis showed that gonorrhea was significantly associated with increased incidence of prostate cancer in North America, but not in Europe or Asia. One possible explanation for this finding is that there was not sufficient published evidence representing European (5 studies) and Asian (2 studies) countries. This is possibly due to the exclusion criteria of the study, since we only included articles published in English. Other potential factors are the relatively low incidence of prostate cancer in Asians and the greater incidence in African Americans.

In this study, we found a significant association between gonorrhea and prostate cancer risk in the studies in which the history of gonorrhea was based on self-reports of the subjects, while the association was insignificant in studies that used medical records or serum antibodies. This finding may be due to the small number of studies that used medical records (2 studies) or serum antibodies (1 study).

The potential biological mechanisms that link gonorrhea and prostate cancer remain unclear. A general association between infections, infection-induced chronic inflammation, and the development of cancer is well-known [38], and increasing evidence indicates that chronic inflammatory states contribute to prostate carcinogenesis [39]. Gonorrhea infection by Neisseria gonorrhoeae has been shown to induce a chronic inflammatory environment within the prostate. Inflammatory cells are recruited after damage or an infection, and they can secrete a large number of cytokines (e.g., interleukin 6) and chemokines (e.g., interleukin 8) that promote the growth of neoplastic cells and ultimately lead to carcinogenesis within the prostate $[40,41]$.
The longer the inflammation persists, the higher the risk of cancer [42]. Evidence from pathology also shows that proliferative inflammatory atrophy, which is often associated with chronic and, at times, acute inflammation, may be the direct precursor lesion to prostatic intraepithelial neoplasia, prostate cancer, or both [43]. In addition, several genes have been studied for their role in prostate cancer development, and in some cases, (e.g., ribonuclease L[RNASEL]/ hereditary prostate cancer 1 [HPC1], toll-like receptor 4 [TLR4], macrophage scavenger receptor 1 [MSR1]) mutations or variants in these genes also increase an individual's susceptibility to infection [44].

The present meta-analysis has some limitations. First, most of the included studies were case-control studies, which are susceptible to recall and selection biases. The statistical effect of these kinds of biases might be reduced somewhat by cohort studies, but we found only 2 suitable cohort studies. Second, the method for determining gonorrhea history or exposure varied across the studies. Gonorrhea history was mostly based on the self-report of the subjects and only 1 study conducted serological tests. This could distort the findings. Third, substantial heterogeneity was observed among the studies, although we were able to find the major sources of heterogeneity through subgroup analyses. Fourth, our results may also have been biased by restricting studies to those published in English, but there was no evidence of publication bias, based on either Egger's or Begg's test. Fifth, the effect of gonorrhea on prostate cancer outcomes may be different for cases of prostate cancer detected in the early stages through PSA screening than for patients who had aggressive fatalities before PSA screening was widely available. However, the pooled ORs in the pre-PSA and PSA-era subgroups were similar. Moreover, data stratified by prostate cancer aggressiveness were not available from the included studies. We also note that, although we performed a careful search for papers published up to June 2014, the 21 included studies all appeared between 1975 and 2011.

\section{Conclusions}

Our analysis found a potential association between gonorrhea and increased risk of prostate cancer, especially among African American males. Because of the limited number of studies, more prospective cohort or intervention studies are warranted to confirm the findings of this meta-analysis. Such findings also warrant investigations of the underlying mechanisms that may be responsible for this association.

\section{Conflict of interest}

The authors declare that they have no conflicts of interest. 


\section{References:}

1. Sigel R, Ma J, Zou Z, Jemal A: Global cancer statistics. Cancer J Clin, 2014; 61: 69-90

2. Ho A, Gabriel A, Bhatnagar A et al: : Seasonality pattern of breast, colorectal, and prostate cancer is dependent on latitude. Med Sci Monit, 2014 20: 818-24

3. Sutcliffe S: Sexually transmitted infections and risk of prostate cancer: Review of historical and emerging hypotheses. Future oncology (London, England), 2010; 6: 1289-311

4. Unemo M, Golparian D, Shafer WM: Challenges with gonorrhea in the era of multi-drug and extensively drug resistance - are we on the right track? Expert Rev Anti Infect Ther, 2014; 12: 653-56

5. Dennis LK, Dawson DV: Meta-analysis of measures of sexual activity and prostate cancer. Epidemiology (Cambridge, Mass), 2002; 13: 72-79

6. Taylor ML, Mainous AG, Wells BJ: Prostate cancer and sexually transmitted diseases: A meta-analysis. Fam Med, 2005; 37: 506-12

7. Sutcliffe S, Giovannucci E, De Marzo AM et al: Gonorrhea, syphilis, clinical prostatitis, and the risk of prostate cancer. Cancer Epidemiol Biomarkers Prev, 2006; 15: 2160-66

8. Cheng I, Witte JS, Jacobsen SJ et al: Prostatitis, sexually transmitted diseas es, and prostate cancer: The california men's health study. PloS One, 2010; 5: e8736

9. Huang WY, Hayes R, Pfeiffer R et al: Sexually transmissible infections and prostate cancer risk. Cancer Epidemiol Biomarkers Prev, 2008; 17(9): 2374-81

10. Hrbacek J, Urban M, Hamsikova E et al: Serum antibodies against genitourinary infectious agents in prostate cancer and benign prostate hyperplasia patients: A case-control study. BMC Cancer, 2011; 11: 53

11. Wells G, Shea B, O'Connell D et al: The Newcastle-Ottawa Scale (NOS) for assessing the quality of nonrandomised studies in meta-analyses. Available from: http://wwwohrica/programs/clinical_epidemiology/oxfordhtm

12. Greenland S: Quantitative methods in the review of epidemiologic literature. Epidemiol Rev, 1987; 9: 1-30

13. Woolf B: On estimating the relation between blood group and disease. Ann Human Genet, 1955; 19: 251-53

14. DerSimonian R, Laird N: Meta-analysis in clinical trials. Controll Clin Trials, 1986; 7: 177-88

15. Crowther M, Lim W, Crowther MA: Systematic review and meta-analysis methodology. Blood, 2010; 116: 3140-46

16. Loeb S, Catalona WJ: Prostate-specific antigen in clinical practice. Cancer Lett, 2007; 249: 30-39

17. Begg CB, Mazumdar M: Operating characteristics of a rank correlation test for publication bias. Biometrics, 1994; 50: 1088-101

18. Egger M, Davey Smith G, Schneider M, Minder C: Bias in meta-analysis detected by a simple, graphical test. BMJ, 1997; 315: 629-34

19. Heshmat MY, Kovi J, Herson J et al: Epidemiologic association between gonorrhea and prostatic carcinoma. Urology, 1975; 6: 457-60

20. Baker LH, Mebust WK, Chin TD et al: The relationship of herpesvirus to carcinoma of the prostate. J Urol, 1981; 125: 370-74

21. Lees RE, Steele R, Wardle D: Arsenic, syphilis, and cancer of the prostate. J Epidemiol Community Health, 1985; 39: 227-30

22. Mishina T, Watanabe $\mathrm{H}$, Araki H, Nakao M: Epidemiological study of prostatic cancer by matched-pair analysis. Prostate, 1985; 6: 423-46

23. Checkoway H, DiFerdinando G, Hulka BS, Mickey DD: Medical, life-style, and occupational risk factors for prostate cancer. Prostate, 1987; 10: 79-88
24. Honda GD, Bernstein L, Ross RK et al: Vasectomy, cigarette smoking, and age at first sexual intercourse as risk factors for prostate cancer in middle-aged men. Br J Cancer, 1988; 57: 326-31

25. Oishi K, Okada K, Yoshida O et al: Case-control study of prostatic cancer in kyoto, japan: Demographic and some lifestyle risk factors. Prostate, 1989; 14: $117-22$

26. La Vecchia C, Franceschi S, Talamini R et al: Marital status, indicators of sexual activity and prostatic cancer. J Epidemiol Community Health, 1993; 47: 450-53

27. Hiatt RA, Armstrong MA, Klatsky AL, Sidney S: Alcohol consumption, smoking, and other risk factors and prostate cancer in a large health plan cohort in california (united states). Cancer Causes Control, 1994; 5: 66-72

28. Ilic M, Vlajinac H, Marinkovic J: Case-control study of risk factors for prostate cancer. Br J Cancer, 1996; 74: 1682-86

29. Hsieh CC, Thanos A, Mitropoulos D et al: Risk factors for prostate cancer: A case-control study in greece. Int J Cancer, 1999; 80: 699-703

30. Hayes RB, Pottern LM, Strickler $\mathrm{H}$ et al: Sexual behaviour, stds and risks for prostate cancer. Br J Cancer, 2000; 82: 718-25

31. Rosenblatt KA, Wicklund KG, Stanford JL: Sexual factors and the risk of prostate cancer. Am J Epidemiol, 2001; 153: 1152-58

32. Sanderson M, Coker AL, Logan P et al: Lifestyle and prostate cancer among older african-american and caucasian men in south carolina. Cancer Causes Control, 2004; 15: 647-55

33. Patel DA, Bock CH, Schwartz $\mathrm{K}$ et al: Sexually transmitted diseases and oth er urogenital conditions as risk factors for prostate cancer: A case - control study in wayne county, michigan. Cancer Causes Control, 2005; 16: 263-73

34. Pelucchi C, Talamini R, Negri E et al: Genital and urinary tract diseases and prostate cancer risk. Eur J Cancer Prev, 2006; 15: 254-57

35. Sarma AV, McLaughlin JC, Wallner LP et al: Sexual behavior, sexually trans mitted diseases and prostatitis: The risk of prostate cancer in black men J Urol, 2006; 176: 1108-13

36. Centers for Disease Control and Prevention: Sexually transmitted disease surveillance 2012. Atlanta: US Department of Health and Human Services; 2013

37. Owusu-Edusei K Jr, Chesson HW, Leichliter JS et al: The association between racial disparity in income and reported sexually transmitted infections. Am J Public Health, 2013; 103: 910-16

38. Lu H, Ouyang W, Huang C: Inflammation, a key event in cancer development. Mol Cancer Res, 2006; 4: 221-33

39. Omabe M, Ezeani M: Infection, inflammation and prostate carcinogenesis Infect Genet Evol, 2011; 11: 1195-98

40. Haverkamp J, Charbonneau B, Ratliff TL: Prostate inflammation and its potential impact on prostate cancer: A current review. J Cell Biochem, 2008; 103: $1344-53$

41. Nakai Y, Nonomura N: Inflammation and prostate carcinogenesis. Int J Urol, 2013; 20: 150-60

42. Chung SD, Lin YK, Huang CC, Lin HC: Increased risk of prostate cancer following sexually transmitted infection in an asian population. Epidemiol Infect, 2013; 141: 2663-70

43. Wang W, Bergh A, Damber JE: Morphological transition of proliferative in flammatory atrophy to high-grade intraepithelial neoplasia and cancer in human prostate. Prostate, 2009; 69: 1378-86

44. Klein EA, Silverman R: Inflammation, infection, and prostate cancer. Cur Opin Urol, 2008; 18: 315-19 